PAP

22,2

100

Received 13 February 2019

Revised 3 June 2019

15 August 2019

Accepted 10 September 2019

HKPAA

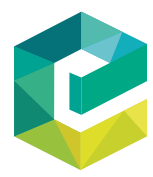

Public Administration and Policy Vol. 22 No. 2, 2019 pp. $100-110$

Emerald Publishing Limited 1727-2645

DOI 10.1108/PAP-09-2019-0016

\section{Crisis responses in public hospitals: case studies in Hong Kong}

\author{
Tai-ming Wut \\ The Hong Kong Polytechnic University
}

\begin{abstract}
Purpose - The purpose of this paper is to investigate the medical incident responses from two public hospitals in Hong Kong, namely, Kowloon Hospital and Caritas Medical Centre, in order to improve the strategic preparation for crisis management in hospitals.

Design/methodology/approach - The paper analyses two medical incidents using Situational Crisis Communication Theory by Coombs (2007). The two case studies presented herein demonstrate the importance of consistency in terms of crisis responses.

Findings - For the first case, the crisis responses from different parties after the incident, including Hospital Authority, the doctor and the nurses from Kowloon Hospital, are contradicting to each other. First, Hospital Authority confirmed that the incident is solely an accident which is a denial response. Second, the doctor passed the responsibility to the nurses which is a scapegoating response. Third, the nurses tend to reduce the responsibility for the death of patient by excusing strategy. As a whole, their responses are inconsistent to each other. For the second case, Caritas had initially denied the responsibilities, but finally had given partial apology under public pressure. That makes people think that Caritas does not really regret.
\end{abstract}

Originality/value - Rebuilding posture should be used instead of denial and diminishment posture. However, public organization and civil servants are reluctant to use a full apology due to possible legal consequences. The apology ordinance would ease the pressure to express regret and sympathy.

Keywords Organizational learning, Crisis response, Situational Crisis Communication Theory (SCCT)

Paper type Research paper

\section{Introduction}

To manage a crisis more effectively and efficiently, public hospitals should have a crisis management policy with clear definition of a crisis. Crisis is "a serious threat that can disrupt organizational operations and has the potential to create negative outcomes such as deaths, injuries, financial loss and reputation loss" (Coombs, 2007, p. 3). Violation of their constituents or stakeholders' expectation is also related to crisis as this may lead to stakeholders' disappointment about the public hospitals in Hong Kong which are managed by Hospital Authority. When making an official announcement about the medical incident, the management of the public hospital might need to seek prior approval from Hospital Authority. It takes time to give a response after a crisis occurs. Media might obtain information or seek for opinions from other unofficial sources when they produce news about the incident. Stakeholders might get false or distorted information and affect their perception about the case.

This paper investigates two public hospital medical incidents in Hong Kong to illustrate how public hospitals can perform or respond better when they manage crises according to the public relation theory - Situational Crisis Communication Theory (SCCT).

(c) Tai-ming Wut. Published in Public Administration and Policy. Published by Emerald Publishing Limited. This article is published under the Creative Commons Attribution (CC BY 4.0) licence. Anyone may reproduce, distribute, translate and create derivative works of this article (for both commercial and non-commercial purposes), subject to full attribution to the original publication and authors. The full terms of this licence may be seen at http://creativecommons.org/licences/by/4.0/legalcode 


\section{Conceptual framework}

The most commonly used crisis communication theories are Benoit's (1995) Image Restoration Theory and Coombs' (2007) SCCT (Dhanesh and Sriramesh, 2018). Benoit (1995) initially points out that an organization must be responsible for its action and need to respond to accusations quickly. Coombs (2007) further proposes a more comprehensive theory on crisis management - SCCT. His theory suggests that the crisis response of an organization could affect how stakeholders perceive the organization in the crisis (Coombs, 2007). That is to say, an organization should be careful in giving a right response. Based on the suggested response strategies by Benoit (1995), Coombs uses attribution theory to account for his theory. When the organization manages the crisis, it is important for them to find out if anyone needs to be responsible for the incident. SCCT tries to address the crisis situation and organization responsibility in order to formulate the appropriate crisis response (Coombs, 2007).

Coombs (2007) explains that there are "three crisis types: victim crisis cluster, accidental crisis cluster and preventable crisis cluster. Examples for victim crisis cluster are natural disasters, rumors, workplace violence and malevolence. Examples for accidental crisis cluster are challenges, technical-error accidents, and technical-error product harm. Examples for preventable crisis cluster are human-error accidents, human-error product harm and organizational misdeeds. Victim crisis cluster has little attribution of crisis responsibility; accidental crisis cluster has moderate attribution of crisis responsibility while preventable crisis cluster has high attribution of crisis responsibility" (p. 142). Crisis in public hospitals might belong to one of these three crisis types. So, the first step is to identify which crisis type the incident belongs to.

The second step is look at the crisis history and prior reputation. If an organization or the public hospitals in this study has a crisis history or negative prior reputation, people might tend to think that the public hospital involved should take greater crisis responsibility. The last step is to select the recommended crisis response strategy. Coombs provides crisis response strategy suggestions based on the information obtained in prior steps. The suggested strategy could be denial posture, diminishment posture, rebuilding posture and bolstering posture depending on the crisis type and crisis history. There are three methods for denial posture: attacking the accuser, denial and scapegoating; and two methods for diminishment posture: excusing and justification. Rebuilding posture could be in the form of compensation and apology. And, bolstering posture takes three different ways in reminding, ingratiation and victimage. Coombs suggests that the affected organization like a public hospital matches its response posture according to the level of responsibility (Coombs, 2007).

\section{Methodology}

Case study method examines a few cases. A number of different features of each case are observed (Thomas, 2011). The process of doing case studies is to study the person, projects, policies, institutions or others involved holistically in different ways and the subject case will be an example of a class of phenomena (Thomas, 2011). In another words, case study is aimed at understanding the details so as to find out what is happening. It is useful to answer the research question in the study:

$R Q 1$. To assess whether the public hospitals involved have made appropriate crisis responses?

Case study is a suitable research tool in analysing crises as it provides an in-depth examination in longitudinal way with information gathered through document collection and analysis (Glesne, 2011), and the progress of the crisis is also captured. In contrast, the quantitative approach usually examines a cross-sectional view of the picture which cannot explain the evolution of the crisis. responses in

public

hospitals

101 
Kowloon Hospital in Hong Kong was established in 1920. It is a public hospital and was previously operated by the Hong Kong Government. It now belongs to the Kowloon Central Cluster and is managed by Hospital Authority. Hospital Authority is operated under the Hospital Authority Ordinance and the Authority is to oversee all the services provided by public hospitals in Hong Kong. Kowloon Hospital provides various medical services including geriatrics, psychiatry, rehabilitation and respiratory medicine. The hospital also provides acute and extended-care services like physiotherapy, occupational therapy, prosthetic and orthopaedic clinical care, nutrition guidance service and speech therapy (Kowloon Hospital, 2018).

The first case is about $\mathrm{Mr} \mathrm{X}$, a 73 years old cancer patient, who underwent total laryngectomy surgery at Queen Elizabeth Hospital in June 2011. The patient had to breathe through a surgical hole in his neck through the throat after the surgery. However, as Mr X had suffered from stroke, he was then transferred to Kowloon Hospital for rehabilitation. However, during Mr X's stay at Kowloon Hospital, Mr X's throat was covered by gauze with tapes which had affected his breathing (Chan, 2013a).

According to Chan (2013a), Mr X's death was caused by the breathing hole in his throat being blocked by gauze. About one week before the incident, Mr X's family members had reported to the nurses a few times about problem with the gauze but no follow-up action had been taken by the nurses.

The Coroner's Court in Hong Kong concluded that Mr X's death was an accident in January 2013. The accident was not associated with any of the doctor or nurses. The court did not state about any potential professional misconduct of the nurse or doctor leading to the death of the patient in the accident.

After the Coroner's Court delivered the judgement, family members of Mr X made a complaint to the hospital for its negligence to the patient. However, the Medical Council of Hong Kong rejected the complaint in August 2015 based on the coroner's court's judgement delivered in 2013. Nevertheless, the family kept on collecting additional evidence in order to prove the judgement from the Coroner's Court was wrong. The Nursing Council of Hong Kong started disciplinary hearing of the involved nurses in November 2015. All the three nurses were found guilty of professional misconduct in March 2016 and were forbidden from practicing for one month (Tsang, 2016) as penalties. The judgement of the Nursing Council of Hong Kong about the gauze blocked the throat event was in disagreement to the 2013 judgement of the Coroner's Court.

In May 2018, the Medical Council of Hong Kong conducted disciplinary hearing of the doctor involved in the case. In the hearing, the doctor was accused of negligence and violated the Rules of Professional Conduct, including failure to stop the patient's permanent tracheostoma - the opening in the windpipe - being managed or treated as a temporary tracheostomy wound. As the doctor did not warn the nurses or other medical staff that the wound was a permanent tracheostomy and finally found guilty of misconduct in fatal blunder (Cheung, 2018).

\section{Crisis type}

There were at least two human mistakes committed in the event; and thus, the case could be classified as under preventable crisis cluster. Preventable crisis refers to the situations when organization placed people at risk, took inappropriate actions or violated a law or regulation. The strong attributions of crisis responsibility will also lead to severe threat on organizational reputation.

The first human mistake is that the doctor involved was found negligence of failing to warn nurses or other medical staff that the wound was a permanent tracheostomy. This might cause death to the patient. 
Another human mistake is about the inappropriate treatment to the patient's permanent tracheostoma. The nurses wrongly put the gauze on the patient's breathing hole in his throat. The victim's family had reported to the nurses few times about the problem with the gauze. The nurses should have taken the responsibility to check and fix the issue accordingly.

These two mistakes can be avoided as it was not related to any technical issue but simply communication breakdown.

\section{Crisis history}

There are at least three negative prior reputation cases of Kowloon Hospital before Mr X's case. The first event occurred in May 2005. Kowloon Hospital had installed circuit television cameras in the wards without consultation with patients. It made the patients uncomfortable and raised issues of privacy (Apple Daily, 2005).

The second case happened in April of 2008. The nurses lost a USB drive stored with the patient's personal and medical records data in the hospital and the incident was discovered one year later. It was a human error since the mistake was made by the nurse (Apple Daily, 2008a).

The third case was that Kowloon Hospital has lost 300 student nurse data and affected both their internal staff and the daily operation of the hospital. It also raised the public concern about the information systems security of Kowloon Hospital. Hospital Authority has demanded Kowloon Hospital to arrange immediate review of their information technology system security in the hospital (Apple Daily, 2010).

Although the above cases had created a bad image for the hospital, it was lucky that no human injury or death was involved. That is to say, the hospital does not have similar case of suspected medical malpractice or professional misconduct involving doctors and nurses. It is concluded that no similar crisis history relating to fatal blunder being happened in Kowloon Hospital before Mr X's case.

\section{Analysis of actual responses}

Crisis managers in the affected organization are advised to manage the crisis quickly. Otherwise, people will turn to other sources to get the case information (Coombs, 2007). There are a number of stakeholders in this case: the doctor and nurses relating to Mr X's death; and Hospital Authority as the one in charge of Kowloon Hospital. Therefore, the response from Hospital Authority represented the standpoint of Kowloon hospital.

After the medical incident, Hospital Authority made a response that it was an accident and no human error was involved. Their statement was based on the judgement from the Coroner's court in 2013. The spokesperson of Hospital Authority stated that there was no crisis (Sun Daily, 2013). Denial posture and denial method were used in such response based on the SCCT.

In the response of the doctor involved after the first judgement of Medical Council of Hong Kong, he has pointed out that this was the fault of the nurses since changing gauze for the patient is the nurses' job duty. He was not involved in the process (Ming Pao, 2018). The job duty of the doctor is to diagnose, follow up and treat the patient. Scapegoating method under the denial posture was used by the doctor. It seems to the author that nurses were blamed for the case.

The doctor's counsel said, "He was extremely regretful about the loss of a patient. He was also a victim of the breakdown of the system of Hospital Authority" (Cheung, 2018). This was not a formal full apology. Instead, it was a partial apology. It avoids bearing full responsibility and legal consequence of the case. The counsel also used victimage method under bolstering as part of the response. However, it might be in the wrong direction according to SCCT since the case does not belong to the victim cluster. 
During the disciplinary hearing of nurses, the nurses involved were trying to minimize their responsibility for the case. The nurses might be responsible because changing gauze is their duty. The nurses did not follow up the complaints from Mr X's family members relating to the problem about the gauze and did not actively seek clarification on the unclear terms (Chan, 2013a). In this case, the nurses argued that they are inexperienced in taking care of the patient after total laryngectomy surgery in Kowloon Hospital; and the hospital has not provided them with any training or instruction for handling such kind of patients (Chan, 2013b). They have followed the normal procedure and the medical notes prepared by the doctor. An incorrect term "tracheostomy" was used in the notes, which made the nurses believe that the medical hole is a temporary tracheostomy only (Tsang, 2016). From this statement, excusing method under diminishment posture was used because the nurses tried to reduce their responsibility for the crisis.

\section{Response according to SCCT}

The SCCT theory suggests that organization uses appropriate response strategy according to the levels of responsibility which determined by the crisis type and crisis history.

According to the analysis of the case, Kowloon Hospital does not have any similar crisis before and the case belongs to a preventable crisis cluster. According to SCCT, the hospital should use rebuilding posture for preventable crisis. Under rebuilding posture, Kowloon Hospital should take up the crisis responsibility and ask for forgiveness by using full apology and/or compensation method. Kowloon Hospital may consider holding a press conference for a quick and complete settlement of the above crisis.

Rebuilding posture may combine with diminishment posture according to SCCT (Coombs, 2007). In this case, Kowloon Hospital could consider using excusing method to minimize the organization's responsibility. Since the nurses and doctor have to take care of a lot of patients in the hospital and human resources shortage in the healthcare and medical sector is always an issue, a common example is that a few nurses have to take care of the whole ward. Mistakes may occur easily, although no one wants it to happen.

Last but not least, bolstering posture can be adapted as supplements to the other response postures. Since Kowloon Hospital has a rather long service history, they should tell the stakeholders about its past good work under reminding method. Ingratiation method can also be used since it is common to see heavy workload and stress for those working in public hospitals.

\section{Organizational learning}

Organizational learning is vital for crisis prevention as people can learn from mistakes. New measures might need to be adopted in order to prevent the same incident from happening again. Thus, the learning ability of the organization needed to be nurtured. There are different learning outcomes to justify the levels of learning after a crisis; the outcome level can be judged by three criteria, including similar mistake, new policy and areas of improvement (Crandall et al., 2010).

For this case, the level of learning after the crisis is midrange outcomes. Kowloon Hospital has not committed similar mistakes after the case. Since there is no precedent of fatal blunder like gauze blocking the breathing hole and caused death to the patient, Kowloon Central Cluster's spokesman said that the Hospital had implemented some improvement measures after the accident, such as organizing staff training to distinguish a permanent tracheostomy from a temporary one (Chan, 2013c). A comprehensive measure in improving ward communication is expected. 


\section{Second case review}

Caritas Medical Centre (CMC) is one of medical services provider under Caritas Hong Kong. The centre is established in 1964 located at Sham Shui Po. The centre is now one of the members in Kowloon West Cluster managed by Hospital Authority and serves 360,000 people in the northwestern part of Kowloon. The centre is an acute general hospital with 1,019 beds. The centre provides 24-h accident and emergency (A\&E) services, full range of acute, extended care, ambulatory and community medical service (Caritas Hong Kong, 2009).

Since $\mathrm{CMC}$ is under Caritas Hong Kong with strong Catholic culture, the centre maintains Caritas motto "Love in the Service of Hope" to provide service. And the centre's mission is "to provide a continuum of the best possible, comprehensive health care for the community in a setting which recognizes and supports the physical, emotional and spiritual needs of patients and their families" (Caritas Hong Kong, 2009).

Medical incidents in Hong Kong hospitals are generally rare; however, different levels of medical incidents have occurred in $\mathrm{CMC}$ in the past.

For the period from 7 to 16 November 2006, unsterilized surgical knives were used in 13 cataract operations at CMC (Hospital Authority, 2006).

On 12 August 2011, another incident incurred relating to blood transfusion for a 64 years old female patient (Hospital Authority, 2011).

On 2 May 2014, a 59 years old male patient died in a medical incident. He had a history of diabetes, and serious coronary disease with completed Percutaneous Coronary Intervention in 2000; and received regular follow-up treatment in the Specialist Outpatient Clinic of Medicine (SOPC) and Geriatric Department $(\mathrm{M} \& \mathrm{G})$ in $\mathrm{CMC}$. However, after examining the patient's medical record, it was found that the SOPC and M\&G did not allocate the prescribed drugs to the patient since 11 March 2014 (Apple Daily, 2014).

On 20 December 2008, it is suspected that a 56 years old man, Yeung Tak Cheung, suffered from heart attack while delivering goods with his son by truck. His son then drove the truck to $\mathrm{CMC}$, parked outside the entrance of Wai Ming Block of CMC and asked for help at the lobby. However, the Caritas staff asked him to call the emergency number 999 as a proper procedure and refused to help. After receiving the report, the Fire Service Department assigned Mong Kok Fire Station to send an ambulance to the location. Unfortunately, there was traffic jam on the way and another ambulance was sent. That caused a delay of 26 min for sending the patient to the A\&E Department and the victim died finally (Hospital Authority, 2008a).

On 21 December 2008, the Executive Director of CMC, Ma Hok Cheung, described this incident as "unfortunate". He admitted that the hospital is lack of clear guideline for their staff to deal with emergencies outside the hospital. However, he insisted that the staff who asked the son to call 999 had already "act according to the guidelines" and had no dereliction of duty. He said that "Our guidelines are just for the accidents inside the hospital. Our hospital has no clear guidelines for our staff if accidents occur outside the hospital". On 22 December 2008, Chow Yat Ngok, Secretary for Food and Health of Hong Kong, condemned that the way that the Hospital Administrator had handled this case was "far from satisfactory". He pointed out that the staff who first arrived the scene has the responsibility to notify emergency department or the person in charge. On the other hand, staff can call 999 for help if they really believe that there is a need to do so. Guidelines should be able to provide direction in dealing with most of the situations, but it is still unable to be applied in all cases. In the hospital, lots of emergencies might happen and the guidelines might not necessarily cover all cases. Chow requested CMC to submit the report of this accident within one week (Hospital Authority, 2008b).

On the same day, the Executive Director of CMC, Ma Hok Cheung; Hospital Authority Chairman, Wu Ting Yuk; and the Chief Executive Officer, Shane Solomon apologized responses in public hospitals 

The Executive Director of CMC, Ma Hok Cheung, admitted that their employees and his treatment process were inadequate including lack of awareness, unclear expression, lack of compassion, etc. Hospital Authority will set up an ad hoc committee to follow up the case. After about six weeks from the report release day, the details of punishment announced. The Executive Director of CMC, Ma Hok Cheung and the A\&E Director, Wu Kui, were prohibited from promotion and pay rise for 14 months. The staff who worked at information desk need retraining. However, Wu Kui appealed to Hospital Authority. The allegations and punishment were taken back at last (Hospital Authority, 2009).

On 7 May 2010, the Coroner's Court ruled that the victim's death was due to natural causes and not belonged to other categories. The evidence was insufficient to support the hypothesis of other classification of death. While the man had potentially fatal disease, there was no evidence to suggest that he was died because of other causes (Headline Daily, 2010).

\section{Actual response}

After this incident, CMC had different responses to the stakeholders at different times. At first, they claimed that no one or any department needed to be responsible for the incident as it was an unfortunate event. On the next day, Ma Hok Cheung, the Executive Director of CMC, modified the previous remark and admitted that the action took was inconsistent to public expectations. Also, apology was given to public after being asked by the reporter. However, he emphasized that the staff involved had followed the guidelines of the hospital and worked hard. He also emphasized that this incident happened at the area outside the hospital which their guidelines had no such coverage for their staff to follow in handling such situation. CMC Chief of Service of A\&E Department, Dr Ng Fu claimed that calling 999 was the best solution because transferring patient to the hospital was the responsibility of the Fire Service Department's ambulance (Apple Daily, 2008b).

\section{Response according to SCCT}

CMC responses show that they seemed to have applied rebuilding strategy as they gave out apology. In theory, their apology is just a partial apology because they expressed their concern and regret only. Apology under rebuilding strategy is a full apology, which the organization should admit to the crisis, accept the responsibility and express their concern and regret. Although they had given out partial apology, it was not made immediately and not at a right timing. Moreover, there is no sign that they had combined other strategies with rebuilding strategies to avoid reputation threat. They also used scapegoating under denial strategy because they claimed that Fire Service Department's ambulance has the responsibility of transferring patient to the hospital. It was unwise to use it as this was not a victim crisis. All these led to reputation threat to CMC.

In this case, crisis is preventable as it is a human-error accident. CMC should use rebuilding strategy. Diminishment strategy and bolstering strategy could also be used. They should use a full apology first, together with excuses that they have limited control to the incident and mainly focus on reminding stakeholders of their past good work.

\section{Organizational learning}

For the level of learning, CMC reached a midrange outcome from the learning from this crisis. After this crisis, although CMC might have committed other medical error it never committed the same type of mistake and no one died or injured caused by delay of treatment outside A\&E Department. Therefore, it is not a failure outcome; it can be either a midrange outcome or success outcome. 
$\mathrm{CMC}$ has then followed the new guidelines from Hospital Authority and implemented "General principles for handling persons requiring emergency medical assistance in the vicinity of HA hospitals and clinics" after this crisis. As a result, CMC adapted a policy change. All along, there was no change to the leadership of the hospital due to the incident, and the two managerial persons only received a penalty of refrain from promotion and pay rise for a short period of time (Hospital Authority, 2008a). This may be regarded as ineffective learning outcome. But since $\mathrm{CMC}$ did not make the same mistake again, $\mathrm{CMC}$ is viewed as achieving a midrange outcome.

An organization which achieved a midrange outcome had a number of learning outcomes. Due to the incident, the organization has made various improvements, such as implementing new guidelines; provision of five sets of portable Automatic External Defibrillator within hospital premises, with training to all the hospital staff; renovation of A\&E Department for the purpose of serving more patients and strengthening the training and manpower in A\&E Department (Hospital Authority, 2008b) The above actions are able to improve the operation and services of CMC.

Last but not least, study of strategy posture towards crisis management is also important in different levels of learning. CMC showed a positive attitude as it has disclosed the full report to the public. The investigation report was attached as a Legislative Council paper and allows public access. Enough transparency could help reputation recovery. CMC is willing to learn, but outcome is not ascertained. This is because the guidelines of Hospital Authority and other improvements actions implemented are all new to $\mathrm{CMC}$ and their staff need time to pick up and to demonstrate whether such new measures could be executed effectively.

To summarize the case, the crisis of CMC achieved a midrange outcome, with new policies and remediation actions implemented within the organization. However, it really takes time for $\mathrm{CMC}$ to better demonstrate that the new measures and policy can be implemented effectively and properly.

\section{Recommendations and conclusion}

The crisis type for the first case is preventable crisis cluster since there were at least two human errors. The doctor was found negligence and had not told the nurses that the wound was a permanent tracheostomy. Also, the nurses wrongly put the gauze covering the patient's throat and blocked his breathing hole (Chan, 2013a; Cheung, 2018).

Based on the analysis for the second case, Hospital Authority, the doctor and the nurses had responded in the crisis. Hospital Authority confirmed that the event is an accident which is a denial response. The doctor passed the responsibility to the nurses which is a scapegoating response. The nurses tended to reduce the responsibility for the death of patient by excusing strategy. According to the principles in SCCT, it is wrong to use denial and diminishment posture at the same time. It gives stakeholders a bad impression that the organization contradicts itself in crisis response. It is because stakeholder outside the organization may find the responses from different parties within the same organization not consistent.

Kowloon Hospital does not have crisis history before and the case here is a preventable crisis. Rebuilding posture should be used instead of denial posture and diminishment posture. In addition, bolstering posture could be used to reduce the damage to its reputation. Kowloon Hospital should tell the stakeholders about its past contributions to the society under reminding method to regain trust.

It is suggested that a minor revamp is needed on the ward communication in Kowloon Hospital. Situation, Background, Assessment and Recommendation communication tool could be used to reduce the barrier during the communication process. It has been used in different healthcare setting (Kallestedt et al., 2015).

As regards the second case, it is recommended that Caritas should do the rebuilding work first and give apology. The expression of concern and regret for the situation might 
make people feel that Caritas is irresponsible. Caritas can also take diminishment strategy which is excusing. Caritas can try to minimize the responsibilities of the organization, for example, it emphasizes that although the staff of Caritas can do better, they do not have the intention to hurt anyone and the development of the situation is out of their control. Moreover, Caritas can take bolstering strategy at the same time; and use reminding method to tell people about their past good work. For example, it can emphasize that Caritas has already made a lot contributions to the society and helped many people in need in the past 44 years. Emphasizing positive things can alleviate the negative impact of the crisis.

Caritas should respond quicker and be consistent. In the case, the accident occurred at 2:00 p.m. on 20 December, but they made the first declaration only in the following early morning (Hospital Authority, 2008a). They missed the news deadline of some media like TV, online. People had already received the message from the media in the evening and midnight. The author points out that if Caritas was able to give a response quickly, the news would not focus only on the victim's son accusing Caritas on the first day. In the first statement, Caritas denied the responsibilities, but provided partial apology later under public pressure (Hospital Authority, 2008a). It made people think that Caritas did not really regret and handled improperly for the case. Second, they should improve the work of controlling claims. As the claims may affect the reputation of the organization, it should investigate the circumstances surrounding the claims. In this case, Caritas did not clarify the rumour about what their clerical staff said. It was claimed that the staff said that "it is not my work"; however, the report by Hospital Authority shown that it is not the fact. Therefore, if Caritas can clarify the claim immediately, the negative feeling from the public could probably be reduced.

In conclusion, for public organizations like public hospitals, the first response the spokesperson makes about the crisis should be as quickly as possible. That can avoid people forming bad first impression from the media based on sources other than official spokesperson. If possible, continuous updates should be released from time to time so that the public hospital can control the mindset of the receivers. Consistency is also an important consideration. It builds up the credibility of the organization's response. Finally, attention should be paid to the openness of the public hospitals. It means availability to the media, willingness to disclose information and honesty. In short, respond quickly, respond with one voice and show openness will be able to make the crisis response more believable and convincing.

\section{References}

Apple Daily (2005), "Kowloon Hospital installed closed circuit television cameras in the wards without notice (九龍醫院錄影病房內情況)”, Apple Daily, 30 May, available at: https://hk.news. appledaily.com/local/daily/article/20050530/4927454 (accessed 26 September 2019).

Apple Daily (2008a), “A nurse lost a USB stored with the patient's data (遺失存有病人資料)", Apple Daily, 27 April, available at: https:/hk.news.appledaily.com/local/daily/article/20080427/ 11039114 (accessed 26 September 2019).

Apple Daily (2008b), “A patient was dead outside Caritas Medical Centre (病人死門前事件)”, Apple Daily, 23 December, available at: http://hk.apple.nextmedia.com/news/art/20081223/12004697 (accessed 26 September 2019).

Apple Daily (2010), “Lost 200 student nurse's data (遺失一個儲存300多名護士學生資料)”, Apple Daily, 20 June, available at: https://hk.appledaily.com/news/art/20100620/14153665 (accessed 26 September 2019).

Apple Daily (2014), “A patient was dead in Caritas Medical Centre (明愛派漏薄血藥害死病人)”, Apple Daily, 2 May, available at: https://hk.news.appledaily.com/local/daily/article/20140502/18707342 (accessed 26 September 2019).

Benoit, W.L. (1995), Accounts, Excuses, and Apologies: A Theory of Image Restoration Strategies, State University of New York Press, New York, NY. 
Caritas Hong Kong (2009), "Medical services", available at: www.caritas.org.hk/en/service/hospital (accessed 26 September 2019).

Chan, T. (2013a), "Old man's airway was blocked by gauze, inquest told”, South China Morning Post, available at: www.scmp.com/news/hong-kong/article/1136231/old-mans-airway-was-blockedgauze-inquest (accessed 26 September 2019).

Chan, T. (2013b), "Kowloon Hospital staff's fatal mistake 'entirely feasible': CUHK professor", South China Morning Post, available at: www.scmp.com/news/hong-kong/article/1138146/ kowloon-hospital-staffs-fatal-mistake-entirely-feasible-cuhk (accessed 26 September 2019).

Chan, T. (2013c), "Cancer man Wang Keng-kao's death was 'an accident': coroner”, South China Morning Post, available at: www.scmp.com/news/hong-kong/article/1138803/cancer-man-wangkeng-kaos-death-was-accident-coroner (accessed 26 September 2019).

Cheung, E. (2018), "Hong Kong doctor Wong Cheuk-yi banned for six months over death of elderly cancer patient Wang Keng-kao at Kowloon Hospital", South China Morning Post, available at: www.scmp.com/news/hong-kong/health-environment/article/2145352/hong-kong-doctor-wongcheuk-yi-found-guilty (accessed 26 September 2019).

Coombs, W.T. (2007), Ongoing Crisis Communication: Planning, Managing and Responding, Sage, London.

Crandall, W., Parnell, J. and Spillan, J. (2010), Crisis Management in the New Strategy Landscape, Sage, London.

Dhanesh, G. and Sriramesh, K. (2018), "Culture and crisis communication: nestle India's Maggi Noodles case”, Journal of International Management, Vol. 24 No. 3, pp. 204-214.

Glesne, C. (2011), Becoming Qualitative Researchers, Pearson, Boston, MA.

Headline Daily (2010), “A patient was dead in Caritas Medical Centre due to natural causes (明愛失救 事件裁定死於自然”, Headline Daily, 6 May, available at: http://news.hkhl.hk/instantnews/ news_content/201005/06/20100506a155248.html?cat=a (accessed 26 September 2019).

Hospital Authority (2006), "Caritas Medical Centre press release surgical knife", available at: www.ha. org.hk/haho/ho/pad/130615e.pdf (accessed 26 September 2019).

Hospital Authority (2008a), "HA chief executive's statement on Caritas Medical Centre incident", available at: www.ha.org.hk/haho/ho/pad/0812225English.pdf (accessed 26 September 2019).

Hospital Authority (2008b), "Caritas Medical Centre response to patient collapsed incident", available at: www.ha.org.hk/haho/ho/pad/081221English1.pdf (accessed 26 September 2019).

Hospital Authority (2009), "HA Chief executive's statement on CMC Report", available at: www.ha.org. hk/haho/ho/pad/090105HEng.pdf (accessed 26 September 2019).

Hospital Authority (2011), "Announcement of an incident regarding blood transfusion”, available at: www.ha.org.hk/haho/ho/pad/111109CMC.pdf (accessed 26 September 2019).

Kallestedt, M., Wallquist, W. and Hultgren, S. (2015), "Team-work and communication in emergency carein a regular ward”, Resuscitation, Vol. 96, Suppl. 1, pp. 96-97.

Kowloon Hospital (2018), "Services", available at: www3.ha.org.hk/kh/ch/services/home.html (accessed 26 September 2019).

Ming Pao (2018), “Doctor expect can deal with the case independently (醫生期望護士處理)", Ming Pao, 9 May, available at: https://news.mingpao.com/ins/港聞/article/20180509/s00001/152 5838246452/ (accessed 26 September 2019).

Sun Daily (2013), “A patient was dead in Kowloon Hospital due to accident (老翁封造口窒息裁死於意外)”, Sun Daily, 30 January, available at: http://the-sun.on.cc/cnt/news/20130130/00407_019.html (accessed 26 September 2019).

Thomas, G. (2011), How to do your Case Study, Sage, London.

Tsang, E. (2016), "Three Hong Kong nurses guilty of professional misconduct after patient dies due to blocked airway", South China Morning Post, available at: www.scmp.com/news/hongkong/health-environment/article/1959241/three-hong-kong-nurses-guilty-professional (accessed 26 September 2019). 
About the author

Tai-ming Wut, Lecturer of SPEED, The Hong Kong Polytechnic University, teaches courses in risk management, crisis management and corporate social responsibility. He received MSc Degree in Mechanical Engineering at The University of Hong Kong and PhD Degree from the University of South Australia. He has taught undergraduate and postgraduate courses in research methods, engineering management and supervised undergraduate engineering projects with tertiary education institutions in Hong Kong. In addition to his teaching experience, he has gained professional experience in engineering management and marketing with multinational corporations. His interdisciplinary research interest areas cover engineering management, corporate social responsibility and crisis management. He has published papers in international journals, such as International Journal of Consumer Studies and Young Consumers. He has also presented his papers in international academic conferences. He is currently Senior Member of Institute of Industrial Engineers and Chartered Marketer with the Chartered Institute of Marketing. Tai-ming Wut can be contacted at: edmund.wut@cpce-polyu.edu.hk

For instructions on how to order reprints of this article, please visit our website: 